\title{
Effects of exogenous melatonin on antioxidant properties of kiwifruit seedling leaves under copper stress
}

\author{
Xuewen Zhao ${ }^{1, a}$, Hui Xia ${ }^{1,2, b}$, Xiu Wang ${ }^{1, c}$, Yulun Guo ${ }^{1, d}$, Xuezhen Yuan ${ }^{1, e}$, Lei \\ Yang ${ }^{1, f}$, Dong Liang ${ }^{1,2, g, *}$ \\ ${ }^{1}$ College of Horticulture, Sichuan Agricultural University, Chengdu, Sichuan, China \\ ${ }^{2}$ Institute of Pomology and Olericulture, Sichuan Agricultural University, Chengdu, Sichuan, China \\ a867396930@qq.com, bsusanxia_2001@163.com, ${ }^{\text {}} 347434587 @ q q . c o m,{ }^{d} 1278414703 @ q q . c o m$, \\ e1723065255@qq.com, ${ }^{\mathrm{f}} 2868055983 @ q q . c o m,{ }^{9}$ liangeast@sina.com
}

${ }^{*}$ Corresponding author. Xuewen Zhao and Hui Xia contributed equally to this work.

Keywords: Kiwifruit; Exogenous melatonin; Copper stress; Antioxidant

Abstract: The one-year-old wild Actinidia deliciosa seedlings were used as materials, by root irrigation of $0.1 \mu \mathrm{mol} \cdot \mathrm{L}^{-1} \mathrm{MT}$ solution and $15 \mu \mathrm{mol} \cdot \mathrm{L}^{-1}$ copper sulfate solution, to investigate the effects of exogenous melatonin on antioxidant properties of kiwifruit leaves under copper stress. The results showed that the relative electrolyte leakage, MDA content of kiwifruit seedlings gradually increased, while $\mathrm{H}_{2} \mathrm{O}_{2}$ content, SOD activity, POD activity and CAT activity increased first and then decreased under copper stress. With the application of exogenous melatonin, the relative electrolyte leakage and the accumulation of $\mathrm{H}_{2} \mathrm{O}_{2}$ and MDA were effectively reduced in kiwifruit seedlings leaves under copper stress, while the soluble protein content and the activity of SOD, POD and CAT were increased. The results indicated that melatonin could reduce the toxicity of copper stress on kiwifruit seedlings and improve the resistance of kiwifruit.

\section{Introduction}

In recent years, with the development of heavy industry, heavy metal pollution of soil is more and more serious. The problem of plant toxicity is increasingly apparent [1]. Copper is an important trace element in plant growth and development, which involved in many physiological processes of plants. But excessive copper will lead to plant poisoning, affect the normal growth and development of plants, and affect the health of human health through the food chain [2]. At present, the effects of copper stress on plants are mainly studied by crops, and horticultural plants are less. Kiwifruit belongs to Actinidiaceae Actinidia Lindl, which has high nutritional value [3]. Melatonin is a signal substance found by Lerner in the pineal gland of cattle [4]. People have found melatonin in higher plants in recent years $[5,6,7]$. Studies have found that melatonin can enhanced plant cells expansion in vitro, promote root growth and regeneration, maintain the integrity of the plant biofilm, and against adverse environmental damage to plants [8]. However, there are few studies on the effects of melatonin on the physiological activities of kiwifruit under heavy metal stress. The aim of this study was to investigate the effects of exogenous melatonin on the antioxidant properties of kiwifruit seedlings under copper stress, so as to provide a theoretical basis for the rational use of melatonin to solve the problem of heavy metal toxicity in kiwifruit cultivation.

\section{Materials and Methods}

Materials and Treatment. The one-year-old wild Actinidia deliciosa seeds were put at $4{ }^{\circ} \mathrm{C}$ refrigerated for 55 days, then to $4^{\circ} \mathrm{C} 16 \mathrm{~h}$ and $24^{\circ} \mathrm{C}$ $8 \mathrm{~h}$ heterotherm treatment for two weeks. Place the seeds under $25^{\circ} \mathrm{C}$ for 10-15 days. Then the seeds are sown in the moist soil, and placed in the culture room with temperature of $20-25^{\circ} \mathrm{C}$ and humidity above $40 \%$. Pouring water one time every morning 
and evening, and 1/2 Hoagland nutrient solution every week for one time. When growed 3 main leaves, the plants were moved to pots containing perlite $\left(10 \mathrm{~cm}^{*} 10 \mathrm{~cm}\right), 3$ plants per pot.

When the seedlings were finished, The seedlings with the same growth condition were divided into control group and treatment groups. Each group of 3 pots were treated with exogenous MT root irrigation and copper sulfate stress. With the $50 \mathrm{~mL} 0$ and $0.1 \mu \mathrm{mol} \cdot \mathrm{L}^{-1} \mathrm{MT}$ solution in the root cap irrigating 5 days later, the seedlings were treated with copper stress. A total of 3 treatments: (1) CK; (2) T1: $\mathrm{CuSO}_{4}\left(15 \mu \mathrm{mol} \cdot \mathrm{L}^{-1}\right)$; (3) $\mathrm{T} 2: \mathrm{MT}\left(0.1 \mu \mathrm{mol} \cdot \mathrm{L}^{-1}\right)+\mathrm{CuSO}_{4}\left(15 \mu \mathrm{mol} \cdot \mathrm{L}^{-1}\right)$. Middle leaves (seven to nine per plant) were sampled after $0,3,6,9$, and $12 \mathrm{~d}$ of treatment. All collected tissues were immediately frozen in liquid nitrogen and stored at $-80^{\circ} \mathrm{C}$.

Physiological Indexes. Physiological indexes. Determination of relative electrolyte leakage refered to Chen et al [9]. Determination of hydrogen peroxide $\left(\mathrm{H}_{2} \mathrm{O}_{2}\right)$ content was reference to Hao et al [10]. The content of malonaldehyde (MDA) was determined by thiobarbituric acid method [11]. Determination of soluble protein content, SOD activity, POD activity, CAT activity refered to Li et al [12]. The above indicators were set three times, and calculated the average value.

Data Handling. Software Excel 2010 was used to calculate the test data and plot. Statistical analysis was performed using software Excel SPSS.

\section{Results and Discussion}

Relative Electrolyte Leakage, $\mathrm{H}_{2} \mathrm{O}_{2}$ Content, MDA Content. Under the condition of adversity, the plant will produce and accumulate $\mathrm{H}_{2} \mathrm{O}_{2}$, increase the membrane lipid peroxidation, produce MDA, seriously damage the biomembrane, increase the membrane permeability and increase the relative electrolyte leakage [13]. In this study, the relative electrolyte leakage of T1 and T2 showed an increasing trend (Figure 1A). T2 was significantly lower than T1, and at $6 \mathrm{~d}, \mathrm{~T} 2$ was decreased most by 42.52\%, compared with $\mathrm{T} 1$ (Figure 1A). The $\mathrm{H}_{2} \mathrm{O}_{2}$ content of $\mathrm{T} 1$ and $\mathrm{T} 2$ increased first and then decreased, and reached the maximum value at 9d (Figure 1B). From 3-12d, T2 decreased by 3.52\%, $9.53 \%, 20.01 \%, 15.39 \%$, respectively, when compared with T1 (Figure 1B). The MDA content of T1 and T2 increased gradually (Figure 2A). At $12 \mathrm{~d}$, T1 increased by $108.94 \%$, and T2 raised by $71.22 \%$, compared with $\mathrm{CK}$ (Figure 2A). The results showed that the relative electrolyte leakage, $\mathrm{H}_{2} \mathrm{O}_{2}$ content and MDA content increase in the leaves of kiwifruit seedlings under copper stress, while the exogenous melatonin pretreatment significantly reduced these indicators to alleviate the accumulation of reactive oxygen species, effectively reduce the membrane lipid peroxidation and reduce the copper stress on kiwifruit seedlings cell membrane damage.

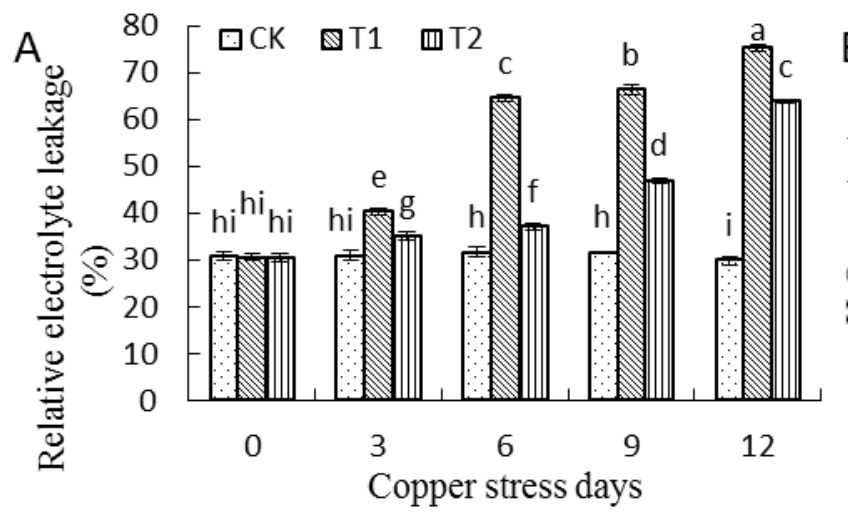

(d)

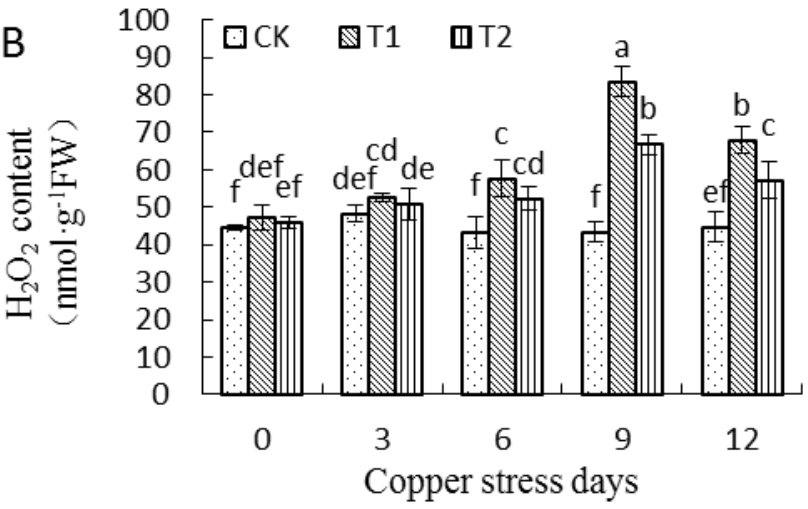

(d)

Figure.1 Effects of exogenous melatonin treatment on relative electrolyte leakage (A) and $\mathrm{H}_{2} \mathrm{O}_{2}$ content (B) of kiwifruit leaves under copper stress

Note: Data with the different letters indicate the difference is significant $(\mathrm{P}<0.05)$. The same as below 

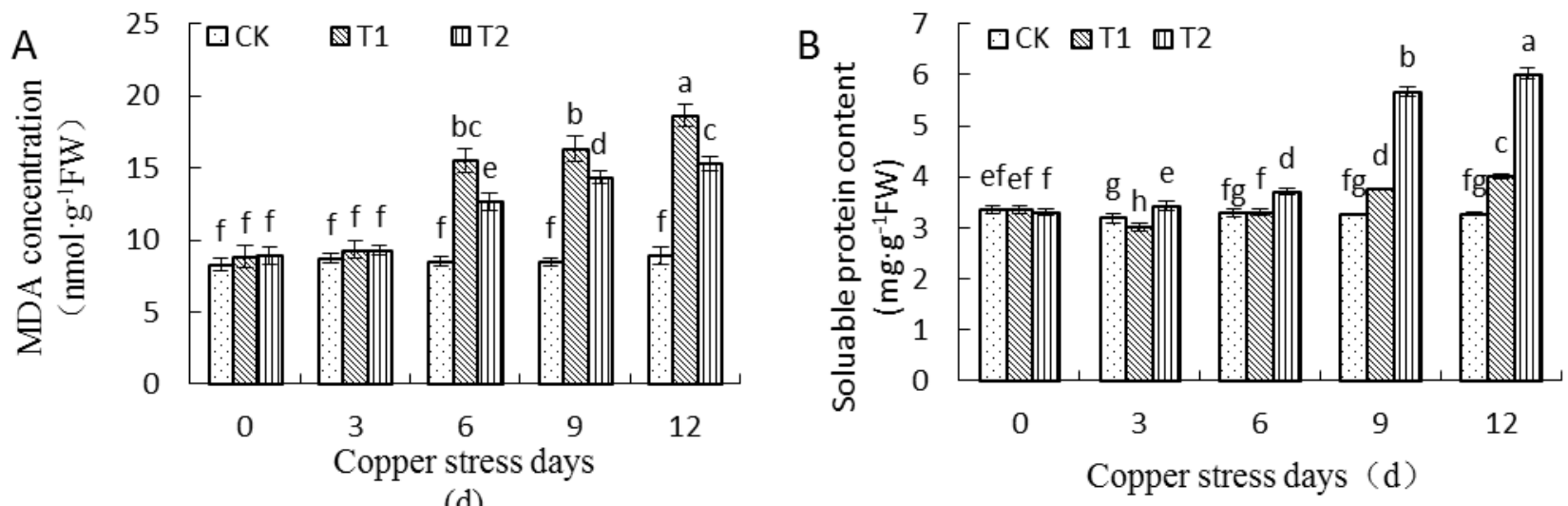

(d)

Figure.2 Effect of exogenous melatonin on the content of MDA (A) and soluble protein (B) of kiwifruit leaves under copper stress

Soluble Protein Content. Soluble protein is an important osmotic adjustment substance in plant. After copper stress, T1 decreased firstly and then increased (Figure 2B). At 3d and 6d, T1 decreased by $10.54 \%$ and $1.50 \%$. Soon the increase of the content may be due to some new proteins produced in the late stage of stress in order to resist copper stress. T2 showed an upward trend, and was significantly higher than CK and T1 at 3-12d. At 12d, T2 increased by 50.20\% compared with T1 (Figure 2B). Thus, exogenous melatonin can ease the degradation of soluble protein in kiwifruit under copper stress, which may be because that the interaction between exogenous melatonin and $\mathrm{Cu}^{2+}$ can alleviate the damage of $\mathrm{Cu}^{2+}$ to biological macromolecules $[14,15]$.

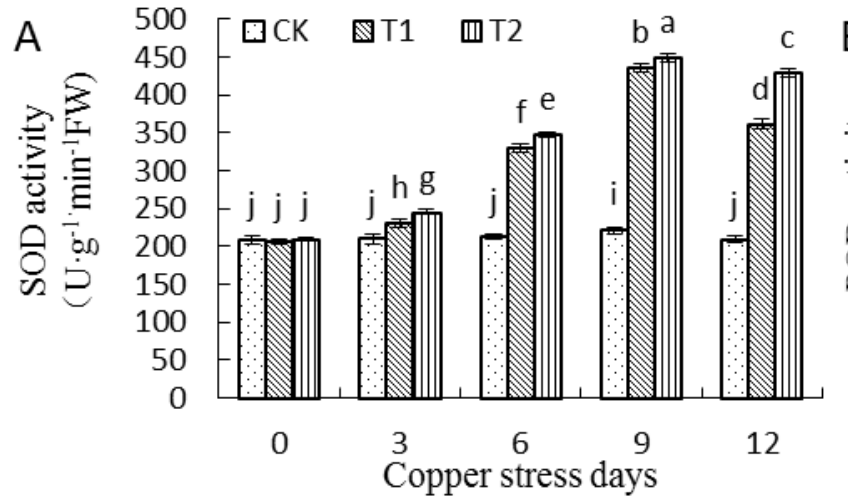

(d)

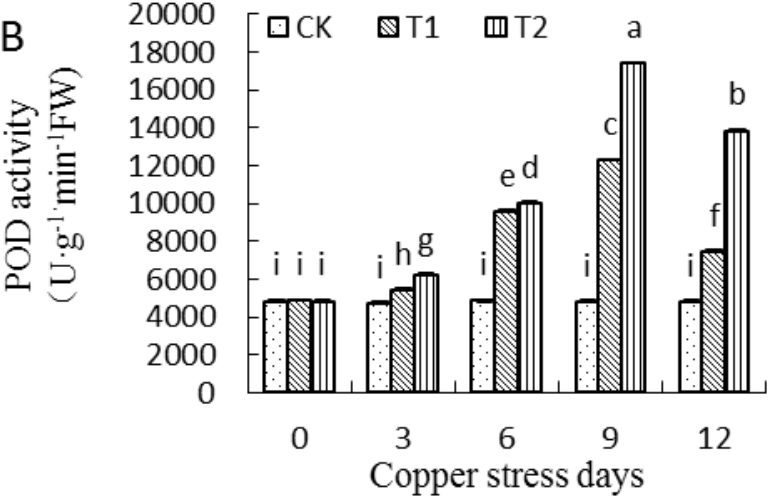

(d)

Figure.3 Effect of exogenous melatonin on the activity of SOD (A) and POD (B) of kiwifruit leaves under copper stress

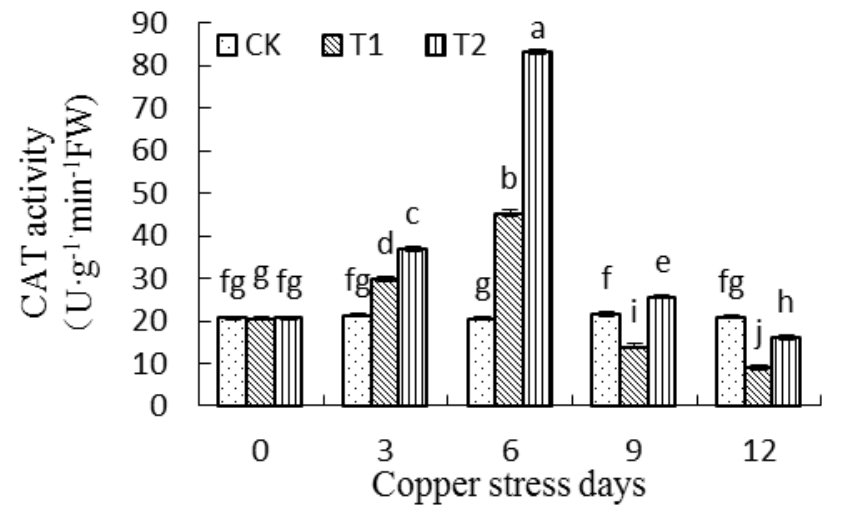

(d)

Figure.4 Effect of exogenous melatonin treatment on CAT activity of kiwifruit leaves under copper stress

The Activity of SOD, POD, CAT. SOD, POD, CAT are important protective enzymes in plant 
antioxidant system. SOD eliminates free radicals in cells by disproportionation and produces $\mathrm{H}_{2} \mathrm{O}_{2}$. POD and CAT further degrade $\mathrm{H}_{2} \mathrm{O}_{2}$ to generate $\mathrm{H}_{2} \mathrm{O}$. The trend of SOD and POD activity are similar (Figure 3). Both T1 and T2 increased first and then decreased, and reached the maximum value at 9d (Figure 3). At 9d, compared with CK, SOD activity of T1 increased by $97.06 \%$, and $\mathrm{T} 2$ increased by $102.83 \%$ (Figure 3A); POD activity rised respectively by $155.48 \% 、 261.67 \%$ (Figure 3B). CAT activity of $\mathrm{T} 1$ and $\mathrm{T} 2$ increased firstly and then decreased, and reached the maximum value at $6 \mathrm{~d}$, which were respectively $45.275 \mathrm{U} \cdot \mathrm{g}^{-1} \cdot \mathrm{min}^{-1} \mathrm{FW}, 83.2 \mathrm{U} \cdot \mathrm{g}^{-1} \mathrm{~min}^{-1} \mathrm{FW}$ (Figure 4). It is concluded that melatonin can enhance the activity of antioxidant enzymes by increasing the expression of encoding antioxidant enzymes genes, and the effect of melatonin on the expression of POD gene is more significant. This is consistent with the results of previous studies [16-17].

\section{Conclusions}

Exogenous melatonin treatment can effectively reduce the relative electrolyte leakage of kiwifruit seedlings under copper stress, maintain the integrity of the cell membrane system, reduced the membrane lipid peroxidation, alleviate the accumulation of $\mathrm{H}_{2} \mathrm{O}_{2}$ and MDA in the plant, increase the content of soluble protein, improve the osmotic adjustment level, enhance the protective enzyme activity, and improve the antioxidant capacity and resistance of kiwifruit.

\section{References}

[1] H. Marschner: Mineral Nutrition of Higher Plants (2nd) (Academic Press, London 1995).

[2] W.S. Shu, K.Y. Yang and Z.Q. Zhang: Journal of Applied and Environmental Biology Vol. 7 (2001), p. 7. (In Chinese)

[3] J.V. Possingham: Scientia Horticulture Vol. 2 (1991), p. 171.

[4] A.B. Lerner and J.D. Case, Y: Takahashi. J Am Chen Soc Vol. 80 (1958), p. 2578.

[5] G.A. Bubenik: Digestive Diseases and Sciences Vol. 47 (2002), p. 2336.

[6] J. Zagajewski, D. Drozdowicz and I. Brzozowska: Journal of Physiology and Pharmacology Vol. 63 (2012).

[7] R. Dubbels, R.J. Reiter and E. Klenke: Journal of Pineal Research Vol. 18 (1995), p. 28.

[8] Y.X. Jiang: Technology Research Vol. 11 (2015), p. 198. (In Chinese)

[9] J.X. Jiang: Experimental Guide of Plant Physiology. 2006. (In Chinese)

[10] J.J. Hao, Z.L. Kang and Y. Yu: Experimental techniques of Plant Physiology (First Edition) (Chemical Industry Press, China 2006).

[11] D.M. Hodges and R.K. Prange: Planta Vol. 207 (1999), p. 604.

[12] H.S. Li: Principle and Technology of Plant Physiology and Biochemistry Experiment (Higher Education Press, China 2000).

13] Z.B. Hao, J. Chang and Z. Xu: Plant Physiology Experiment (Harbin Institute of Technology Press, China 2004).

[14] J. Limson, T. Nyokong and S. Daya: Journal of Pineal Research Vol. 24 (1998), p. 15.

[15] N. Susa, S. Ueno, Y. Furukawa, J. Ueda and M. Sugiyama: Toxicology and Applied Pharmacology Vol. 144 (1997), p. 377.

[16] N. Zhang, H.J. Zhang and Y.D. Guo: Journal of Pineal Rasearch Vol. 56 (2004), p. 39.

[17] N. Zhang, Q. Jiang and D.B. Li: Journal of China Agricultural University Vol. 19 (2014), p. 54. (In Chinese) 